\title{
Thinking as Drawing - Reflections on a Drawing that No Longer Exists
}

\author{
By Teresa Belo Rodeia*
}

Architects use graphic representation to invent architectural objects. As it is not the architect who builds the architectural objects, that work is done by others, it is through confrontation with the object's representation, and not through confrontation with the construction thereof, that such objects are created. One could accept, perhaps it is even desirable, that the drawing is a translation of the thought, returning it to the creator in a new form; but one would also have to acknowledge that the drawing never reveals itself to be an exact record of the thought process. Nevertheless, it is through the drawing that thought becomes understandable, so any lack of correspondence between thought and its representation must be regarded as something more than a deficiency. It is also important to consider the drawing to be more than just a reflection of the thought one wishes to develop further. In contemporary architectural design practice the drawing no longer enjoys the hegemony that a certain nostalgic idealisation of the work of the architect would confer upon it, but the relationship between the drawing and the design thought process remains closely knit, in that the creation of architectural objects continues to be dependent on representation thereof. Using a specific design process as an example - the Gallo House (1968-1970), in São Pedro de Moel, Portugal, by Manuel Mendes Tainhain which the drawing was a decisive presence, this paper seeks to study the relations between thought and representation beyond the general notion of a certain subordination of the representation to the thought that brings it about. It is through the drawing that the thought can be realised, for it then to be confronted with the drawing.

\section{Introduction}

Architects make use of representation in conceiving architectural objects. As it is not architects who build those architectural objects, for that is the work of others, said objects are engendered proceeding from confrontation with their representation, and not from confrontation with their construction.

It may be admissible - perhaps even desirable - that the drawing translates the thought, returning it to whomever thinks it, but it must be recognised that what the drawing reveals is never an exact reflection of the thought. Nevertheless, it is through the drawing that the thought is made understandable, so that it is important to consider that this non-alignment between thought and representation is more than just an inadequacy. One must also consider that the drawing is more than just a reflection of the thought that one wishes to elaborate.

The presence of the drawing in contemporary design practice may no longer enjoy the dominant status it was once given by the nostalgic idealisation of the work of the architect, but the relationship between the drawing and the

\footnotetext{
*Assistant Professor/Research Fellow, Lusíada University, Lisbon/CITAD, Lusíada University, Lisbon, Portugal.
} 
design thought process remains a questioning one, as the invention of architectural objects remains dependent on representation.

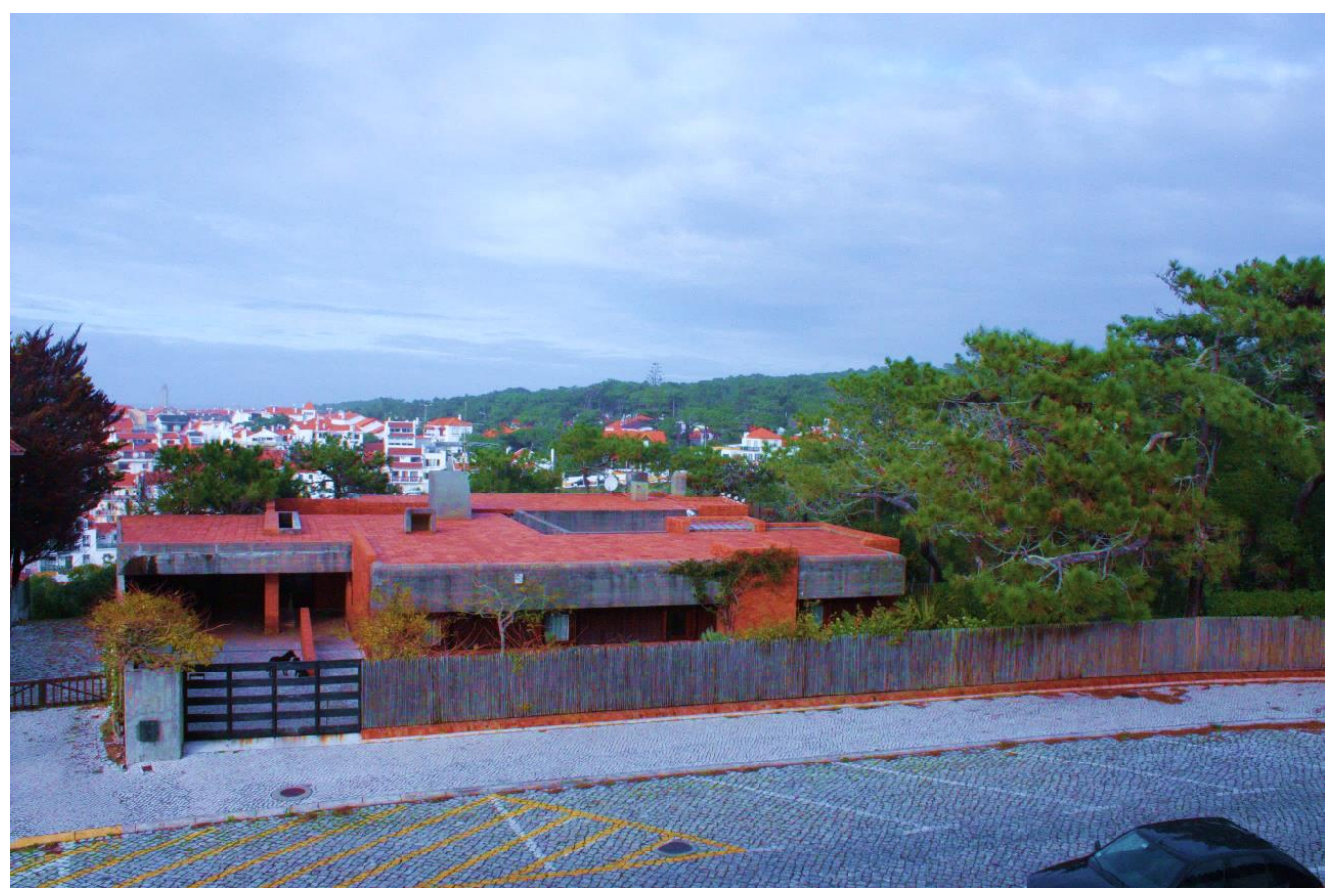

Figure 1. Gallo House, São Pedro de Moel, Portugal

Source: Teresa Belo Rodeia, 2012.

Based on a specific design process - for the Gallo House (1968-1971) in São Pedro de Moel, Portugal (Figure 1), designed by the architect Manuel Tainha ${ }^{1}$

1. Born in Paço de Arcos in 1922, Manuel Tainha graduated in Architecture from the Lisbon School of Fine Arts in 1950. He worked with Carlos Ramos and at Lisbon City Council, where he interned under the planner Faria da Costa until 1954.

He was a member of the Architectural Association of London from 1959 onwards. His body of work is one of the most important in the context of Portuguese architecture in the latter half of the $20^{\text {th }}$ century, with several of his buildings featuring on architectural heritage lists and/or on the Iberian DOCOMOMO register. Amongst other awards, he is the recipient of the AICA Prize (1990), the Valmor Prize (1991) and the National Prize for Architecture (1993). He took part in several exhibitions in Portugal and abroad and also represented Portugal at several congresses of the International Union of Architects (UIA) - Lisbon, 1953; The Hague, 1955; and Paris, 1965. He also participated in successive editions of the General Fine Arts Exhibitions in Lisbon between 1950 and 1956. Some of his works were included in the Exhibition of Portuguese Architecture (London, 1956) and the Contemporary Portuguese Architecture show (Washington, 1958).

Between 1955 and 1961 he was co-promotor and co-organiser of the Survey of Portuguese Regional Architecture, which was carried out under the auspices of the National Union of Architects. The survey was published in book form under the title Arquitectura Popular em Portugal [Popular Architecture in Portugal] (1961). He was co-founder and editor-in-chief of the magazine Binário in 1958 and has authored some of the most important texts on Portuguese architecture, many of them published in magazines and later compiled in books, specifically Arquitectura em Questão [Architecture in Question] (1994), Textos do Arquitecto Manuel Tainha [Texts by Architect Manuel Tainha] (2000) and Manuel Tainha, Textos de Arquitectura [Manuel Tainha, Texts on Architecture] (2006). He was awarded the UIA's Jean Tschumi Prize for his critical work in 2002. 
(1922-2012) - where the presence of the drawing plays an all-important role, this paper sets out to examine the relationship between thought and representation beyond the context of a certain state of subservience on the part of the representation to the thought that gives rise to it.

\section{Notes for Reflection on the Relationship between Design Thought and the Drawing}

"During succeeding centuries the importance of drawing, which still in the sixteenth century had sufficient novelty for the authors of treatises to draw special attention to it, became taken for granted. Thus, for example, in the early nineteenth century, the French theorist J. N. L. Durand wrote, 'Drawing is the natural language of architecture.",2

Durand's words cited here by Forty provide insight into the long-established dominance of the drawing in the work of the architect. By arguing that "drawing is the natural language of architecture", or in other words, that the drawing is the perfect means for architecture to find its natural expression, also means that the drawing is at the genesis of architecture, i.e. is at the base of the process that originates it. Drawing would also be the natural language of the architect. In the drawing, the architect finds a clear expression of their thought. Thought and drawing could therefore be understood as merging, becoming one. "What we find here is the belief that drawing can be a neutral medium, through which ideas pass as undisturbed as light through glass." 3 The drawing is, therefore, merely a vehicle for the thought, and goes no further. Assuming that the drawing was involved in defining the thought beyond that more utilitarian dimension would mean, perhaps, to question the intellectual dimension of the work of the architect. The drawing helps to define architectural objects, and makes their communication to those who commission them and those who will build them easier. If mastery of the drawing was reduced, could possibly even perturb that communication. However, it has always been as an instrument, i.e. as a means for the architect to record their thought and to communicate it, that the drawing has been looked at. "Such was, until recently at least, the most common view of drawing within architectural practice." It is important, however, to consider another meaning of that understanding of the drawing. The assumption of the drawing as the "natural

He devoted a significant part of his life to teaching architecture. He was co-founder, director and teacher of the Artistic Training Course at the National Society of Fine Arts (1965-74) and had teaching roles at the Department of Architecture at the Lisbon School of Fine Arts/Technical University of Lisbon (1976-1992), the University of Coimbra's Department of Architecture (19891993) and in the Architecture degree course at Lusíada University in Lisbon (1993-2010). Amongst other positions he held, he was President of the National Union of Architects from 1960 to 1963.

In 2000 Manuel Tainha was awarded the title of Grand Officer of the Order of Prince Henry the Navigator by the President of the Portuguese Republic. He died in Lisbon in 2012.

2. A. Forty, Words and Buildings: A Vocabulary of Modern Architecture (London: Thames and Hudson, 2001), 31.

3. Ibid.

4. Ibid. 
language of the architect", to use Durand's words, even if that is meant as an appraisal, ends up revealing its relativisation.

Understanding the relationship between design thought and the drawing may benefit from reflection on the implications of a translation process.

Translating obviously involves transposing something from one milieu to another. It is an idea most closely associated with language, but one that can also be used in relation to the representation of architecture. An architectural object can be translated to a drawing, just as a text in one language can be translated to another language. But one must acknowledge that the transfer is never completely transparent. Despite all intentions to the contrary, the result of the translation may not correspond, at least in part, to the original source. Only a certain distancing from this constraint - a suspension of critical disbelief, as we will see - can explain the continued belief that the texture of a text remains intact after a translation. Accordingly, only a distancing from this consequence of the translation makes it possible to understand that one continues to trust in the adoption thereof. This distancing process should also be identified in the representation of architecture. "I would like to suggest that something similar occurs in architecture between the drawing and the building and that a similar suspension of critical disbelief is necessary in order to enable architects to perform their task at all.",5

Said suspension of critical disbelief has not always been acknowledged, and for this reason assessment of the drawing in architectural design practice is somewhat abstruse. At the root of valuation of the drawing, one discovers a detachment in terms of its role in the design process. Evans also argues: "while on the one hand the drawing might be vastly overvalued, on the other the properties of drawing - its peculiar powers in relation to its putative subject, the building are hardly recognized at all.",6

Valuation of the drawing would be different, as indeed would the understanding of its use in architectural design, if one were to assume the difference that it inherently constitutes in relation to the architectural object it represents. Evans again: "Recognition of the drawing's power as a medium turns out unexpectedly, to be recognition of the drawing's distinctness from and unlikeness to the thing that is represented, rather than its likeness to it, which is neither as paradoxical nor as dissociative as it may seem."7

Without calling into question the ideas proposed by other authors, and whilst recognising the pioneering nature of Evans' work, the ideas advanced by Daniel M. Herbert in his text of 1993 entitled 'Architectural Study Drawings' are of particular pertinence for this understanding of the drawing. Herbert examines the drawing not so much as a finished object or as an order of thought, but observes its elaboration process and assumes that its "incomplete" and "contingent" character is decisive for the design process. Study drawings, to quote Herbert directly, "are made mark by mark within a design task that evolves in real time, and are always

5. R. Evans, Translations from Drawings to Building and Other Essays (London: Architectural Association, 1997), 154.

6. Ibid.

7. Ibid. 
poised between an unresolved past and an unpredictable future." ${ }^{\circ}$ The drawing ceases to be seen as a means of registering a prior thought; it is through the drawing process that the thought is established. For this reason, the relationship between drawing and design thought process should be reassessed. To quote Herbert again: "These drawings are significant, then, not as completed objects but as part of a graphic thinking process. Understanding study drawings requires considering how mental and graphic processes interact in the real time of the design task."

In a way - one could argue on the basis of Herbert's ideas - the drawing adds itself to that which it is supposed to represent, thus influencing the development of its own definition, i.e. the evolution of the design process thinking. It is thus that the value of the drawing for the architect's thought process should be understood.

Based on the framing made possible by these references, it was understood that realisation of this research project would have to involve immersion in the development process for the Gallo House design. Only thus could one observe the to-and-fros between thought and representation.

Some of the known study drawings were analysed in this investigative project with a view to identifying the complex thought process they were embodying, a web of thought that was always somewhere between "an unresolved past" and "an unpredictable future," 10 as Herbert put it. To a certain extent those drawings were re-executed, thus reconstructing the web of thought. A creative thought process was penetrated and reconstituted. The aim was not, however, to carry out a rigorous archaeological study of the design; but rather, based on the drawings gathered, to identify an underlying logic to the formulation and generation of the process, making it possible to reveal the meaning of the drawing through the constitution of the thought. At all times in the investigative work the approach to understanding of the drawing took into consideration the lack of definition that any design project goes through, even if the built work is known. Looking back, it may seem that the final product, i.e. the built work, was there in the drawing. However, a drawing is always carried out prospectively, meaning that that to which one seeks to give body is as yet unknown.

\section{Gallo House Design Process}

"As it is meant to be a permanent home, the house should provide the various and complex activities inherent in family life with an ambience of relative stability and identity [...] so that the notion of house is superimposed by the richer and more complex notion of place."11

\footnotetext{
8. D. Herbert, Architectural Study Drawings (New York: Van Nostrand Reinhold, 1993), 2.

9. Ibid.

10. Ibid.

11. M. Tainha, Memória Descritiva (Marinha Grande: Câmara Municipal da Marinha Grande, Processo camarário no 1299/1969, 1969).
} 
At the end of the 1960s Manuel Tainha (1922-2012) was commissioned by Beatriz and Manuel Gallo to design a house for them in São Pedro de Moel, essentially a summer residential village on the Portuguese coast.

The village of São Pedro de Moel is set in the pine forests of Leiria and is crossed by a small tree-covered valley, at the bottom of which runs the Ôlho stream. The oldest part of the village's built fabric is located at the bottom of the valley next to the sea and on the northern slope of the valley.

From the mid- $20^{\text {th }}$ century onwards the settlement was subject to considerable expansion, ${ }^{12}$ extending all around the old nucleus. The plot for the Gallo House was located in one of these areas. Roughly trapezoidal in configuration, and sloping considerable, the site was exposed to the north and was bound by the avenue providing access to it and the central valley, which it overlooks, enjoying expansive views over the adjacent and distant surroundings - the pine forest to the east, the village houses to the north, and the beach and ocean to the west.

The house was originally thought of as a permanent home for the Gallos and their three daughters, ${ }^{13}$ and was therefore to include three distinct areas: the living/reception spaces - with living and dining room and a play room; the private bedroom areas - with a suite for the parents, a guest bedroom and two bedrooms for the children; and a service area containing a kitchen, pantry and housekeeper/ servants' rooms. In addition to these areas, the respective sanitary installations were to be included and also a shelter for cars/carport.

These were the basic programmatic requirements under which the thought process was begun by the architect, Manuel Tainha: a site opening up at one end onto an exceptional landscape, but also fustigated by winds from the north, that was to be the site of a house that, it was hoped, could become a home.

The architectural design project for the Gallo House commenced in 1968. Construction work began in late 1969. Work on the final architectural design and the furniture/interior design continued alongside the construction work. ${ }^{14}$ The house was completed in 1971, with the Gallo family moving into the house in June of that year. ${ }^{15}$

The study drawings that have survived until today are only a small part of those produced throughout the design process for the house. Of these drawings, I would suggest analysing and interpreting a number of them that provide insight into the role of the representation in the evolution of the design thought process.

The first work meeting between the Gallos, as developers, and the architect Manuel Tainha resulted in a number of drawings ${ }^{16}$ that seem to have defined, from

12. The expansion of the built-up area of São Pedro de Moel is taken into consideration in the Preliminary Urban Development Plans of 1947 and 1962 by the archiect José de Lima Franco (1904-1970) (E. Quinta, S. Pedro de Moel: Um Refúgio Moderno. Master Dissertation. Faculdade de Ciências e Tecnologia da Universidade de Coimbra, 2010, 40-44).

13. During the house's construction process the Gallos' fourth and last child was born.

14. The furniture design project for the Gallo house, which was considered an integral element of the whole design, was also the work of Manuel Tainha.

15. The house remains in the possession of the Gallo family today.

16. The study drawings that resulted from that first meeting appear as a whole to be quite informal. They take up both sides of a sheet of thick paper $(140 \mathrm{~g})$ measuring $32.20 \mathrm{x} 19.85 \mathrm{~cm}$, together with a text describing the programme. They generally take the form of floor plans where 
the outset, the exact location of the structure. It was decided immediately to place the house close to the western side of the plot, with the aim of freeing up a spacious area for an outdoor/garden area and, at the same time, making it possible to create a connection to the beginnings of the valley that crosses São Pedro de Moel, thus extending it the site visually.

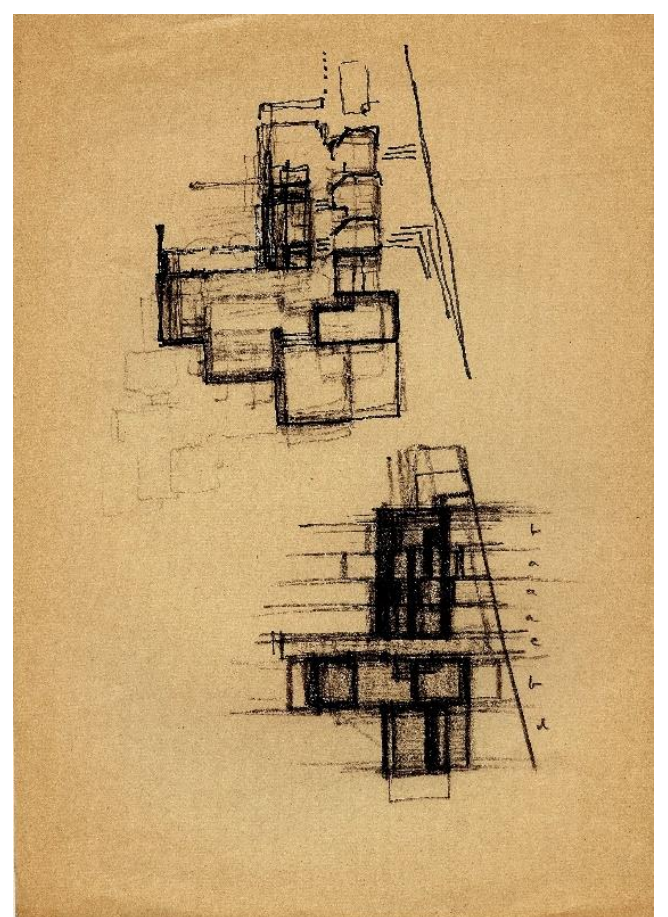

Figure 2. Gallo House Study Drawings. Graphite on Paper, $21.0 \times 29.7 \mathrm{~cm}$ Source: FCG - Biblioteca de Arte e Arquivos, Espólio Manuel Tainha, DVD 4, Sketch 3.

Figure 2 features two plans for the house facing south that experiment with the possibilities of articulation between the various spaces within the house and between the house and the western boundary of the plot. In both solutions the living/reception spaces are laid out on lower levels of the land to the north and the bedrooms are laid out in a row facing westwards and separated from the bathrooms by a corridor providing access to the bedroom area. Between the living spaces and the private spaces, which are perpendicular to each other, giving rise to a protected exterior area, the kitchen area is proposed, as well as the entrance to the house.

In the uppermost plan (in Figure 2), the living area is fragmented in design and is laid out on different levels, linked by steps, which enhances identification and a certain degree of independence of the three separate zones that make up that

the whole plot of land is represented, with the built structure occupying the western half only. Despite the informal nature of the drawings - reflected in particular in their speed of execution and a certain lack of concern with proportion between the parts that make up the whole - they already explore the possible links between the various areas of the house, placing the living spaces at the north end, where the site affords more generous views, and the bedrooms parallel to the plot's western boundary. These two areas occupy two bodies perpendicular to each other, forming an Lshape, with the kitchen area at their intersection. 
area. These should be, if one reads the drawing from north to south, the dining room (given the closeness to the kitchen) and the living rooms. The latter mainly face south, looking onto the aforementioned protected exterior area, whereas the former seems to establish a relationship with another exterior area (a terrace?) that occupies a position to the east/north. The kitchen area is proposed for the space between the dining room and the entrance to the house.

The sensitive adaptation of the house to the site topography, which is patent in the living/reception spaces, continues on into the circulation space which crosses the interior space longitudinally, providing access to the bedrooms, which are also laid out on different levels. The house hugs the terrain and 'becomes one' with it.

The split levels in the house's interior spaces are accompanied by the exterior access route to the house, which runs parallel to the bedroom volume in a southnorth direction. The house itself is accessed in a west-east direction, which requires an inflection in the access route from the entrance to the plot. This access route also serves to separate the bedrooms functionally and spatially from the reception/living spaces.

The lower plan drawing in Figure 2 is more undefined. Whereas the uppermost plan on the same page is made up of several layers, revealing vestiges of other alternatives that were rejected, in this plan the lack of definition derives precisely from the graphic density that results from the superimposition of layers that simultaneously seem to be testing various alternatives in the search for an architectural solution, gauging proportions and configurations and alternating positions for the various parts that make up the whole. Nevertheless, a number of principles are maintained, namely the generic configuration of the whole building and the relative positioning of its constituent parts: the living spaces are still at the north end and the bedrooms still form a line facing south. However, the living spaces now take an L-shaped form and, together with the kitchen area, are clearly separated from the bedroom area by a transversal circulation space. This rupture between the functional areas enhances a frank physical and visual relationship between the house entrance and the interior of the site.

The superimposed solutions experimented with in this plan are based on a modular, rhythmic metric which is given a written reference - "b, a, a, a, c, b, d" probably in an endeavour to geometrise the architectural design. The bedrooms remain along the western plot boundary - represented by an oblique line - and the plan experiments with disalignment of the bedroom modules, emphasising the idea of the metric by giving it a possible volumic and spatial correspondence. What we have here is a drawing representing investigation of form and compositional experimentation.

The plan in Figure 3 (above, left) would seem to be an attempt to summarise the preceding solutions while seeking the stabilisation of the architectural proposal. It is a clear and legible representation, where the proportions are more calibrated, whereby this control may also come from the metric investigation represented in the preceding plan (Figure 2, lowermost plan) - lines, occupied spaces and voids interact in a search for compositional balance. Now the formal variants are no longer superimposed, in layers, on the same drawing, but are shown side by side. 


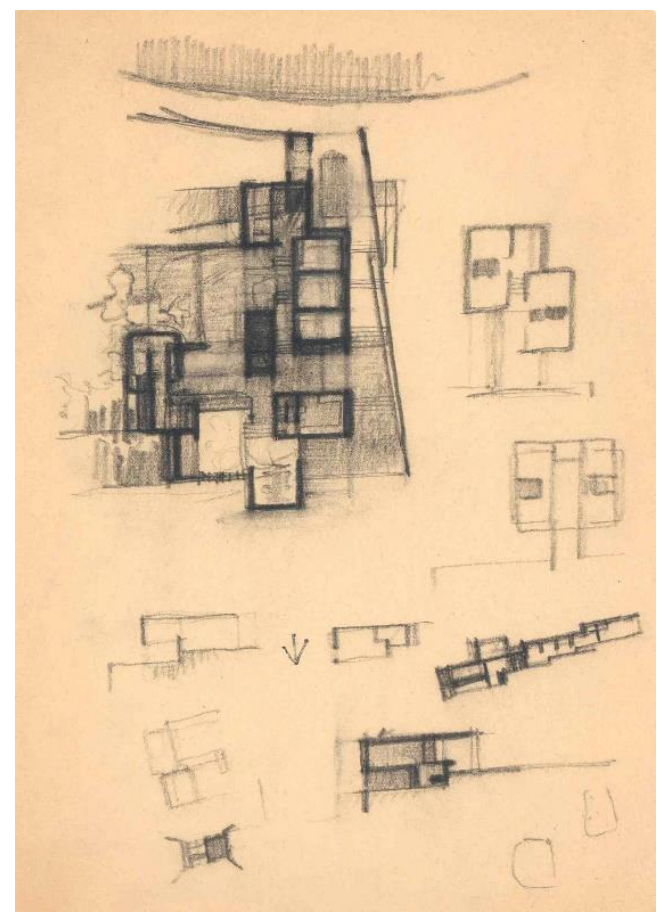

Figure 3. Gallo House Study Drawings. Graphite on Paper, $21.0 \times 29.7 \mathrm{~cm}$ Source: FCG - Biblioteca de Arte e Arquivos, Espólio Manuel Tainha, DVD 4, Sketch 7.

In this plan, in addition to the western plot boundary - already shown in previous drawings - the southern boundary is also drawn in, providing greater insight into the relationship that the construction establishes with the plot and with the street providing access to it. Also, given the graphic choices in this drawing the use of stain - one has a better idea of the surface area of the house, both within and without its physical limits. Nevertheless, the architectural solution remains essentially the same: the bedroom volume is laid out in the south/west of the house, the reception spaces occupy a north/east position, with the entrance space continuing to simultaneously separate and create a relationship between these two functional areas.

In this more distended and fragmented solution - which comes closer to the experimented solution in the uppermost plan in Figure 2 - a contained exterior space is shown, slotted in between the bodies that house the living spaces and the bedrooms and protected from the street by a wall; the figure of a patio, previously hinted at, seems to emerge now with greater clarity. ${ }^{17}$ The patio now takes on the role of a central space in the composition, towards which the whole house converges, and by means of which multiple relationships can be established between the house and the remaining free area of the plot, i.e. between the house and the pine forest to the east. Simultaneously, from the patio, and not just from the living spaces, it is also possible to read the landscape on the basis of the views over the village (north) and the ocean (west). To use the words of João Rodeia:

17. In the upper plan in Figure 2 there was a timid representation of a wall, which seems to correspond to the initial layers of the drawing. 
"[t]he patio is engendered by the whole while, nevertheless, it continuous to be the spatial bosom of domestic life." 18

The architectural solution also reveals a certain dichotomy between visual and physical courses, favouring oblique visual lines and orthogonal physical courses; in other words, the orthogonality of the planes that make up the composition and enhance the physical courses of the house is counteracted by the obliquity of its visual permeability, enhanced by the way the living space is configured: divided up by spaces that seem to slide into each other, while maintaining their adjacency. Rodeia once again confirms this design organization: "[c]ontrary to what the corporal evidence might lead one to expect, the effect of rediscovery is immediately recognizable as the main protagonist of this story between intricate and intriguing directions that entwine and mould the spatial plot to daily life." ${ }^{19}$ This particular configuration of the living spaces allows, on the one hand and as already mentioned, for identification and a certain degree of autonomy of the various spaces that compose it. On the other hand, and as a result of the aforementioned condition, there would seem to be a great variation in the environmental qualities of these spaces, with the possibility of altering the intensity and source of the daylight, or generating interior/exterior relationships through expansion or contraction of the transition spaces, etc. "In this sense, the design simulation remodels the space in progressive articulations and inflections, makes it pulsate in successive contradictions and expansions, adjusts topographical platforms and juxtaposes them with various openings and cavities that take on a life of their own.",20

This potential exploration of the house's spaces in ambience terms seems to be given expression in the way how Manuel Tainha creates a relationship with the plot. Rejecting conventional directional exposure - to the north - he opted to present his plans with a southern orientation, denoting its positioning in the interior of the plot and reflecting on the house from that position, ${ }^{21}$ i.e. from the inside outwards.

The design brief for the house called for a shelter for cars or carport. In the drawings in Figure 2 one can see the tentative location of such a facility next to the entrance to the plot, on the southern side. This position is confirmed in Figure 3, even if the formal alternatives explored on the right side of plan - where other possible solutions for the southern end to the building are explored - do not take this into consideration.

In Figure 3 there also emerges for the first time a section/elevation that runs through the length of the plot and the house, confirming some information and adding more. It confirms that the house adapts to the topography, overcoming the slope through the use of split levels; it also presents a solution for the roof, also consisting of various levels, thus, to a certain degree, also accompanying the

18. J. B. Rodeia, “A House on the Beach - With regard to Manuel Tainha's Architecture," in Manuel Tainha: Projectos 1954-2002 (ed.) J. Neves. Porto: Edições Asa: 2002, 31.

19. Ibid.

20. Ibid.

21. Exposure to the south is a constant in the plans throughout the whole Gallo House design project - from the earliest sketches to the formal submission of the design to Marinha Grande Town Council. 
natural lay of the land. There is also a volume that sticks out on the roof above the kitchen area, which has its obvious correspondence in the plan in the representation of a vertical access integrated into the living spaces and next to the kitchen. The drawings also experiment with a fenestration metric in the bedroom volume, giving greater meaning to the modulation expressed in the plan. And the drawing also shows the relationship that the northern end of the construction - for which the living spaces are proposed - could establish with the land and the surroundings, with more alternatives for that relationship being investigated in the other cross sections that are located in the lower part of the graphic representation.

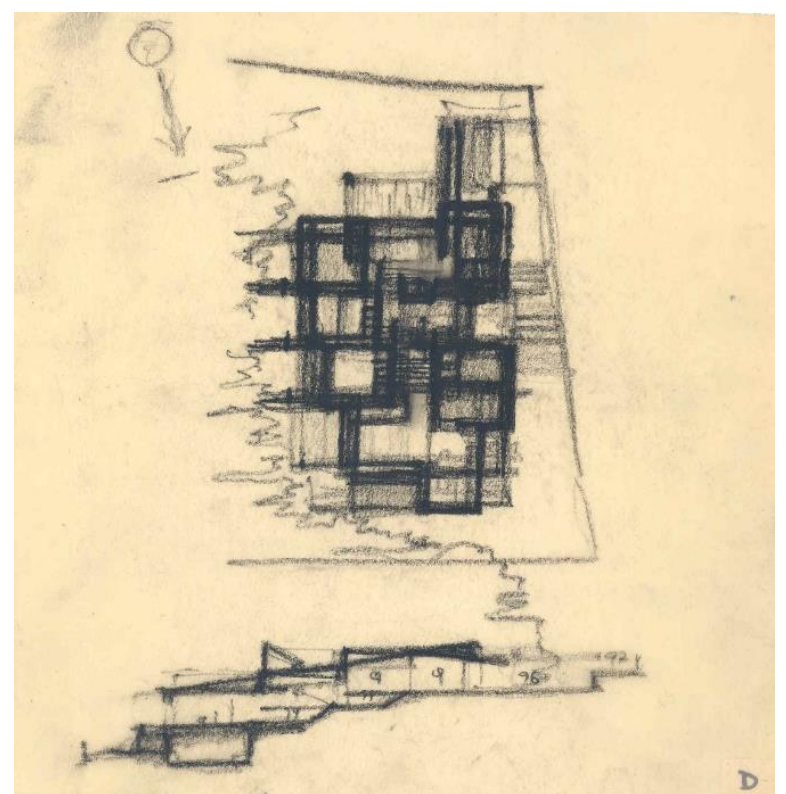

Figure 4. Gallo House Study Drawings. Graphite on Tracing Paper, 20.4 x 21.0cm Source: FCG - Biblioteca de Arte e Arquivos, Espólio Manuel Tainha, DVD 4, Sketch 4.

Whereas the plan in Figure 3 represents an attempt to stabilise the architectural design, that in Figure 4 once again reflects a degree of formal investigation that questions the architectural solution arrived at in the preceding plan. Figure 4 is an extremely dense representation containing multiple layers which presents new possibilities in terms of spatial organisation. Instead of just coming up with a solution, in this representation diverse possibilities are placed in confrontation. The drawing serves to question, investigate and reflect.

As it is drawn on translucent tracing paper it seems to have been produced on top of the preceding drawing (Figure 3, ${ }^{22}$ using its overall metric and the generic composition of the living spaces, but experimenting a new solution for the bedrooms - with exposure to the east and south. The bedrooms now occupy the space that was the patio, which no longer exists at the centre of the composition and the house becomes more compact in terms of volume. The entrance to the house is now moved to the south as a result of both the move of the bedrooms from the west to the east and the extension of the kitchen area.

22. It was possible to confirm this through a reading and subsequent superimposition of one drawing over the other. 
At the entrance to the plot, the new plan references the parking space, which is confined by a plane on the eastern side that protects a new exterior space (patio) and also limits access to and visibility into the plot's interior. In the plan in Figure 3 , the same limit takes the form of a volume that is placed between the entrance to the plot and its interior.

The drawn representation of the southern, western and northern plot boundaries allow for an understanding of the dimensions of the building, which, as it is on one floor only, takes up a considerable area of the plot. Areas of vegetation (suggested by dynamic drawing strokes) surround the house to the east and north. This may be the indigenous maritime pine coverage which would continue on into the valley from there.

Figure 4 also features a longitudinal section of the house, this time drawn on a scale identical to that of the plan. It is a section along the central distribution space, intersecting the steps that link the three levels of the interior space; it also makes the first reference to the elevation measurements. The uncertainties are clearly being reduced little by little, and greater clarity is given to the way in which the building 'hugs' the land, even seeming to openly assume the idea of sinking the house in relation to the road outside the plot. The area between the house and the street, to where the patio is now moved, features a covered exterior space - also represented in the plan - which serves as a transition space between the interior and exterior. This new location diminishes the patio in terms of its protagonism; by forfeiting its central position (in Figures 2 and 3) it no longer assumes its role as an agglutinating element for the house's various functional areas, thus losing its former relationship with the living spaces.

On the opposite side of the house, to the north, there emerges a basement level, already shown in the section drawings in Figure 3, above which the living spaces are located; the latter areas are thus elevated above the natural lay of the land, providing views over the landscape in the direction of the village and the ocean. This suggestion is reinforced by the representation of two (human) figures in the centre of the space.

The section drawing also studies - based on the solution already experimented with previously, which consists of horizontal slabs on various levels - a new alternative for configuration of the roof. It examines the possibility of a single, sloping roof slab that follows the slope of the land, thus enhancing the unity of the interior space. This solution may have been learnt on a visit that Manuel Tainha made around this time to the Maison Carré ${ }^{23}$ in France, completed by Alvar Aalto (1898-1976) in 1963. It emphasises the principles of the desired union of the structure with the natural terrain, which had always been an idea that was present throughout the design process.

The importance of Aalto's oeuvre for the work of Tainha is best understood from a later interview suggestively published under the title Manuel Tainha em directo: sobre Alvar Aalto e outros assuntos. [Manuel Tainha live: on Alvar Aatlto and other isues] "What I essentially assimilated from Aalto was not his drawings, his figurative models, his way of drawing a ceiling, or a pillar, etc.; it was

23. Manuel Tainha himself made reference to the Maison Carré as a design inspiration for the Gallo house in a conversation we had on 4 November 2011. 
something else, something he wrote about in an article I translated: a method, a way of working, of attacking the drawing and losing the fear of the blank paper." 24 Tainha's translation of Aalto's text was published in Arquitectura magazine in $1953 .{ }^{25}$ Many of Tainha's written thoughts on architecture and his approach to design can be traced back to Aalto's text.

A volume that is triangular in cross section stands out on the roof. As it comes with a lightly drawn oblique line linking it to the ground floor of the house, the line indicates a physical connection between the two spaces.

The various plans presented in Figure 5 show the experimentation with new possibilities for the spatial and functional organisation of the house. Previously studied alternatives are explored with regard to the positioning of the bedroom spaces and new proposals are made; also, new options for the location of the living spaces are tested, with them unfolding to the south for the first time; the architectural design is compacted and extended in different areas, essentially playing possibilities against each other in the search for the architectural solution.

In plan 'a', which comes close to the approach experimented with in Figure 4, the bedrooms once again face south/east and the living spaces face north, separated from the former by the kitchen area and the house entrance space. The patio remains between the built structure and the southern plot boundary; it now establishes no relationship with the living room and, consequently, none with the surrounding landscape. However, this solution does assume with greater clarity slight translations in the four modules on the east side of the house - containing the bedrooms and living spaces; this movement provides a visual connection from all said spaces in terms of the uninterrupted views northwards. This interpretation would seem to be confirmed by the vertical lines drawn in the distribution spaces between the modules, indicating visual interior-exterior permeability.

24. Author's own translation. Original text: “O que no fundo eu assimilei do Aalto não foram os seus desenhos, os seus padrões figurativos, a maneira de desenhar um tecto, um pilar, etc. mas outra que está já contida num artigo que eu traduzi, ou seja: um método, um modo de trabalhar, de atacar o desenho e perder o medo do papel em branco". Tainha, "Interview with João Belo Rodeia for Jornal Arquitectos," Architects Journal 152 (1995): 26.

25. A. Aalto, "O Ovo de Peixe e o Salmão," Arquitectura 46(Feb) (1953): 15-16. Whilst Aalto's text was first published in 1947 in a bilingual version (Italian and English) in Domus magazine, under the titles Architettura e Arte Concreta and Architecture and Concrete Art respectively (Aalto, “Architettura e Arte Concreta," Domus 223-5(Dec) (1947): 103-115,) Tainha translated it from a French-language version, titled L'ouf de poisson et le saumon, that was published in the Swiss magazine Das Werk in 1949 (Aalto, “L'Oeuf du Poisson et le Saumon," Das Werk: Architektur und Kunst 36(2) (1949): 43-44. 


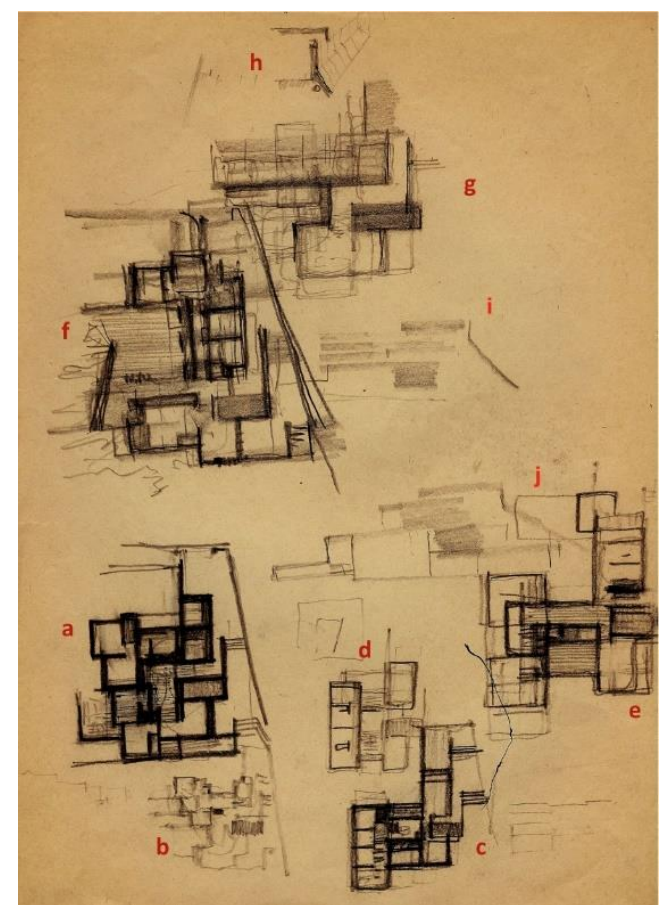

Figure 5. Gallo House Study Drawings. Graphite on Paper, $21.0 \times 29.7 \mathrm{~cm}$ Source: FCG - Biblioteca de Arte e Arquivos, Espólio Manuel Tainha, DVD 4, Sketch 6.

In a small and faint drawing on the bottom of the page (plan ' $b$ '), the shift in the modules on the eastern side is accentuated and the bedrooms are separated from the living spaces by a void that constitutes an exterior relaxation space that also makes it possible to open up the living spaces to the plot interior. This solution seems to have its genesis in plan ' $a$ ', which features an outdoor space contained by two planes adjacent to the living spaces.

Plans 'c', 'd' and 'e' present new compositional experiments. In plan 'c' all the bedrooms on the east are now moved to the northern plot boundary, in an aligned row configuration without any discontinuities. The living spaces occupy almost all of the rectangular body that stretches in a south-north direction from the entrance to the plot and seemingly occupying the central zone in the composition. Accordingly, the living spaces win back their relationship with the plot interior through the contained exterior space on the south/east - and with the surrounding landscape to the north; however, they are now interrupted by the kitchen area.

Plan ' $d$ ' presents a similar solution, making it essentially a variation of the aforementioned solution: bedrooms on the east side and the living spaces on the west, the latter divided up by the kitchen area, which probably separates the dining room from the living room. However, this solution does not seem to foster such a direct relationship between the living spaces and the free area of the plot to the east.

While plan 'e' seems to be a further development of prior solutions, its proposals allow for different readings, as they study diverse superimposed alternatives that reflect the evolution of the design thought process: on the one hand, the bedrooms seem to be integrated into the body on the east of the composition; whilst, on the other, their positioning with a south/west exposure 
seems to be experimented with again. The living spaces are located on the lower elevations, partially superimposed on the bedrooms and occupying the whole north front of the structure. They unfold in three spaces that are gradually recessed in relation to the most advanced plane of the façade, and the generic composition is distended. The patio, an exterior space contained to the north and west by the building itself, regains its central role in this solution, and is able to bring the diverse interior spaces into relationship with each other.

Despite the density of the drawings, which results from the gradual process of refinement of the architectural design, the solution experimented with in plan ' $f$ ' does not feature superimposed alternatives. The distended solution from the preceding composition (plan 'e') is maintained, which results essentially from the placement of the patio at the centre of the composition. However, the solution still reflects transformation, coming close to the seemingly stabilised solution presented in Figure 3: the patio is now formed by the walls of the bedrooms, which form an L shape to the south and west, and the living rooms and kitchen (to the north), and also by a confining wall to the east, the slanted orientation of which seems to establish a parallel relationship with the eastern boundary of the plot. The patio's central position confers upon it an agglutinating dimension, which is enhanced by the fact that the circulation courses around it create visual relationships from all the spaces in the house to all the spaces in the house, creating infinite possibilities. It also makes something no less important possible: it opens up the living spaces to the south - the most favourable exposure direction which can be shared with other window openings to the north, where the living spaces also benefit from attractive views of the village and the sea, but where the house also needs greater protection.

Plan 'g' would seem to correspond to an increase in the central area of plan ' $\mathrm{f}$ ', albeit with the proportions altered and, apparently, the patio being left out: the similarity in the drawings of the kitchen area would seem to corroborate said correspondence. Exploration of a new possibility by the author - in this case, for the first time throughout this process, the positioning of the bedrooms facing south - may have caused him to momentarily leave out some of the elements of the problem to be solved, such as the patio, but which remain implicit in the process and may be returned to later on.

A small drawing - identified as drawing ' $h$ ' - is located on the top centre of the page, close to the partial plan ' $\mathrm{g}$ '. It is a vertical section perspective which, I believe, corresponds to the finishing work on the building at the southern end, in the area to which the bedrooms were transferred. This section plainly shows the concern with the constructivity of the house: the relationship between the roof and the walls, and between the walls and the floor slab is studied; a drainpipe is shown on the outside of the building where it meets the terrain, avoiding that water can infiltrate from the exterior into the interior which is laid out at lower elevations.

On the set of drawings that make up Figure 5, one should also note the following. It has been registered that plan ' $a$ ' is similar to the approach experimented with in Figure 4 that that the more schematic plan ' $b$ ' is a variation thereof. Despite the fact that plans ' $c$ ' and ' $d$ ' reveal a certain degree of proximity in formal terms to plan ' $a$ ', the bedrooms are moved to the east side of the house 
and the living spaces to the west for the first time. Plan 'e' is a further development of the preceding plans, but it contains, in superimposed layers, variants that were to be developed further in plan ' $\mathrm{f}$ '. Finally, in plan ' $\mathrm{f}$ ', which would seem to be a consequence of all the previous options, returns to the solution presented in Figure 3 , which constitutes a prior phase in the design process, as if it were necessary to confirm or reject an architectural solution through confrontation with the representation thereof, whereby it is apparently just as important to represent what one wants as what one does not want. Renzo Piano's statement on the importance of the drawing for understanding architectural problems is an example of this phenomenon: "Unless you draw something, you do not understand it. It is a mistake to believe that now I understand the problem and now I draw it. Rather, right at the time you draw you realize what the problem is and then you can rethink it.",26

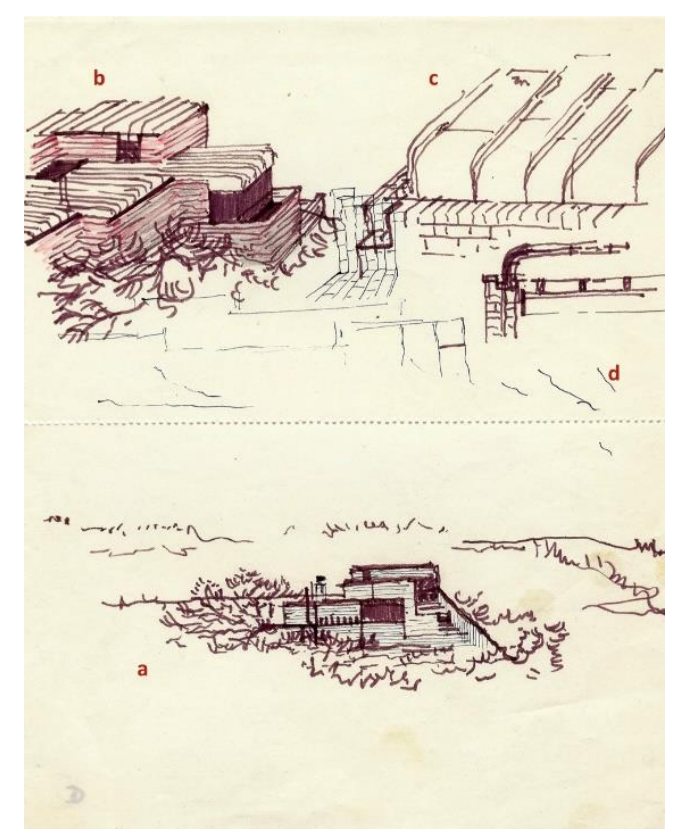

Figure 6. Gallo House Study Drawings. Ink and Coloured Pen on Paper, $16.4 x$ $21.0 \mathrm{~cm}$

Source: FCG - Biblioteca de Arte e Arquivos, Espólio Manuel Tainha, DVD 4, Sketch 5.

The bottom half of Figure 6 features a drawing of the north elevation of the house and the immediate surroundings. As with the other plans analysed, the lot boundaries are also represented on this drawing: to the west, a diagonal line denotes the boundary to the neighbouring plot; to the south, the horizontal line behind the vegetation represents the road providing access to the house. It is interesting to note that drawings ' $i$ ' and ' $j$ ' in Figure 5 already feature the preliminary structure on which the construction of this elevation is based; the difference being that now the drawing shows with greater conviction and clarity

26. Renzo Piano quoted by Robbins. E. Robbins, Why Architects Draw (Cambridge and London: MIT Press, 1994), 127. 
what was still uncertain and murky in the aforementioned drawings. The expression in the drawings would seem to confirm this.

As stated above, this elevation is shown with its surroundings, i.e. the vegetation around the house. This means that the impact of the construction can be minimised, as the existing pine tree coverage is maintained, both in the unbuilt space within the plot (east) and on the northern slope, which was an aim of the design project from the outset.

As far as the external composition of the house is concerned, the elevation reveals a split-level roof that accompanies the sloping terrain and manages to establish a formal correspondence to the fragmentation shown in the plans analysed. By the Figure 6 stage, the author seems to have given up on the possibility of a single slanting roof slab, as presented in Figure 4.

Although the elevation does feature a large opening, there is a predominance of occupied spaces over voids because, as already mentioned, this orientation (to the north) provides the house with more advantageous vistas, even though it will also require more protection from the north. This drawing also for the first time alludes to building materials through the graphic textural effect, given to the façade plane.

The perspective drawing in the upper half of Figure 6 (drawing ' $b$ ') translates in three-dimensional terms what is already implicit in the elevation. It provides a clear reading of the compositional relationship between the various volumes that finish the building on the northern end; it provides insight into how the roof folds over the vertical surfaces and how the large opening is enhanced by a volume that stands out against the landscape; textural differences between horizontal and vertical planes are explored, indicating the use of different materials and differentiation in terms of expression between the structure and the surrounding vegetation is confirmed.

Drawings ' $c$ ' and ' $d$ ', which are, respectively, a perspective and a construction section, develop further the investigation into finish between horizontal and vertical planes, i.e. between the roof and the walls. The difference in the materials that constitute or cover these planes is made evident by the variation in the dimensions of the modules that form the planes, indicating different stereotomic representations. One now understands the reasoning behind the graphic differentiation between the roof and the walls in the preceding drawing (' $b$ '), which is now reflected by an assumed planimetric discontinuity of these two building elements that is shown in both drawings. The section (drawing ' $d$ ') studies the constructional feasibility of the architectural solution, seeking correspondence with the image that is desired for the building.

The most impactful drawing in Figure 7 is a floor plan. Despite its limited size - its scale is less than 1:200 - the plan is very detailed and rigorous, to which contributed the use of a fine drawing instrument. One can also detect the use of lines drawn in advance in pencil which served as a support for this drawing. The drawing also makes use of supplementary annotations, such as dimensional references in some spaces/rooms, written notes and schematic sections, which, together, complement the information in the plan. 


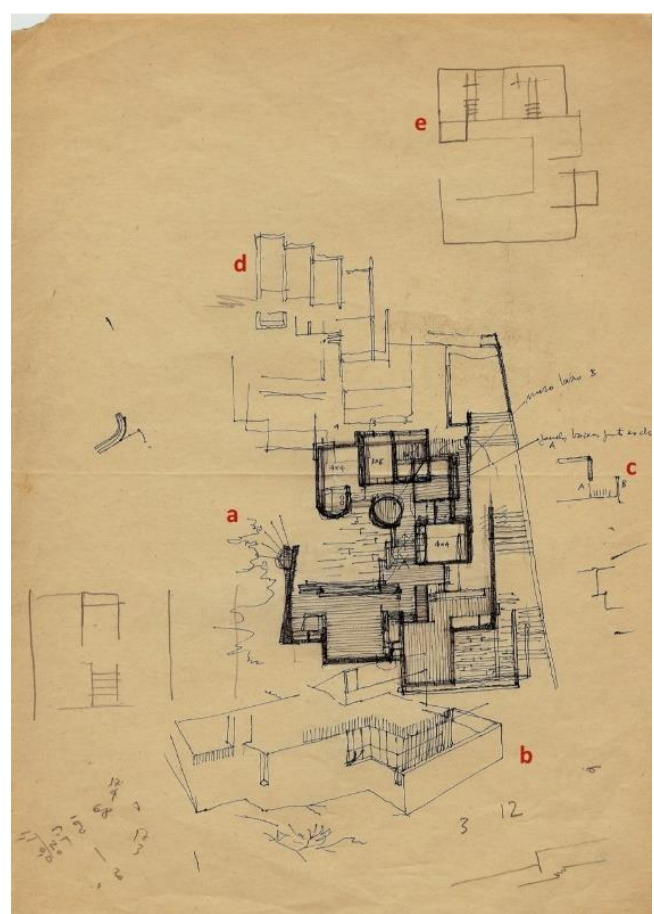

Figure 7. Gallo House Study Drawings. Graphite and Ink on Paper, $21.0 \times 29.7 \mathrm{~cm}$ Source: FCG - Biblioteca de Arte e Arquivos, Espólio Manuel Tainha, DVD 4, Sketch 2.

The architectural solution proposed in this drawing comes closest to drawing ' $\mathrm{f}$ ' in Figure 5, which in turn was a further development of Figure 3 and a prior plan in the upper half of Figure 2. The house is developed around a central patio, with most of the bedrooms at the southern end and taking in the corner to the west, whilst the living spaces and kitchen areas face north. The entrance to the house separates the private bedroom areas from the living spaces and at the same time connects the exterior to the remaining area of the plot by means of the patio.

The shared spaces are divided into two areas: the dining room, which is linked to the kitchen and has an exterior terrace facing the sea (northwest); and the living spaces, whereby one of them is more contained and features a fireplace, as evidenced by the chimney in the lower perspective drawing (drawing ' $b$ ').

In addition to the chimney, a construction element already shown in the elevation drawing in Figure 6 (drawing ' $a$ '), the perspective drawing clarifies the compositional relationships the house's living spaces establish between each other, and complements and adds to the information in the plan. The way in which the dining room opens up onto the landscape is maintained, the relationship between that space and the adjacent terrace is clarified, and one also understands that the other living spaces are more closed in with regard to the exterior, but that this is offset by more intimate relationships with the patio. However this drawing features a new corner window that provides an interesting framed view over São Pedro de Moel valley to the northeast. The perspective also reveals a single-level roof, intersected by a volume (a triangular prism) that provides access to the roof, a solution already experimented with in the section drawing in Figure 4.

The solution for the roof in terms of the number of levels would seem to correspond to a reduction in the split levels inside the house: the bedrooms, living 
spaces and entrance space are now laid out on three different levels, whereby the entrance is on the intermediate level. Perhaps the decision taken in drawings ' $\mathrm{g}$ ' and ' $h$ ' of Figure 5 to sink the bedrooms in relation to the elevation of the land, led to that choice.

Despite the considerable level of detail in the plan - revealed, amongst other things, by the refinement in the proportions, the references to the room dimensions, stereotomic representation of the floor coverings, indication of mobile equipment - the architectural proposal still contains a number of uncertainties that require more investigation. There is hesitation in relation to the location of the staircase providing access to the bedrooms, solutions are still being tested for the southwest corner and the oblique intersection of the volumes there, a circular space and other semi-circular spaces to house sanitary installations are still being worked on, and the slant of the eastern patio wall seems to be confirmed. In the upper drawings, alternatives for the southern end of the structure are tested: experimenting with uniform translations of the bedrooms (drawing ' $d$ ') or placing them all in one row (drawing 'e').

To the right of the plan there is a small sectional drawing (drawing ' $c$ '), which provides clarification as to the finished look on the western side. The window heights ("low windows next to the floor A") coincide with the adjacent wall ("low wall B").

Before interpreting the final architectural solution, which is partially expressed in the plan and cross section in Figures 8 and 9, two architectural drawings submitted to Marinha Grande Town Council as part of the building permit process for the Gallo House, it is important to point out that the group of study drawings analysed herein is only a small part of those actually produced and only a part of those that have survived until today. Furthermore, the study drawings were accompanied by technical or architectural drawings - not only for greater geometric control of the architectural solution in key phases of the creative process, but also because of the need to communicate to the developer the solutions arrived at over a design project period that lasted roughly for one year.

The main plan for the house (Figure 8) shows the whole plot in the drawing; the building occupies a considerable area of the plot. The occupied surface area results from the option for a single-level solution, with the house built around a relatively spacious central patio, which requires a distended layout of the spaces.

The purchase of the neighbouring plot to the east during the Gallo House design process released Tainha from the need for a more compact layout, which was indeed evident in some of his initial investigation, and no doubt was decisive for the final design choice.

On the basis of the main plan (Figure 8) and a longitudinal section (Figure 9) one can confirm that the functional areas of the house are clearly identified - with the bedrooms at the southern end, the living spaces at the north and the kitchen area, entrance space and covered parking spaces occupying a central position. Identification of these areas is enhanced by a certain degree of simplification of the configuration in relation to the design proposals in the preceding plan (Figure 7) and other earlier plans, which feature a more indented layout. 


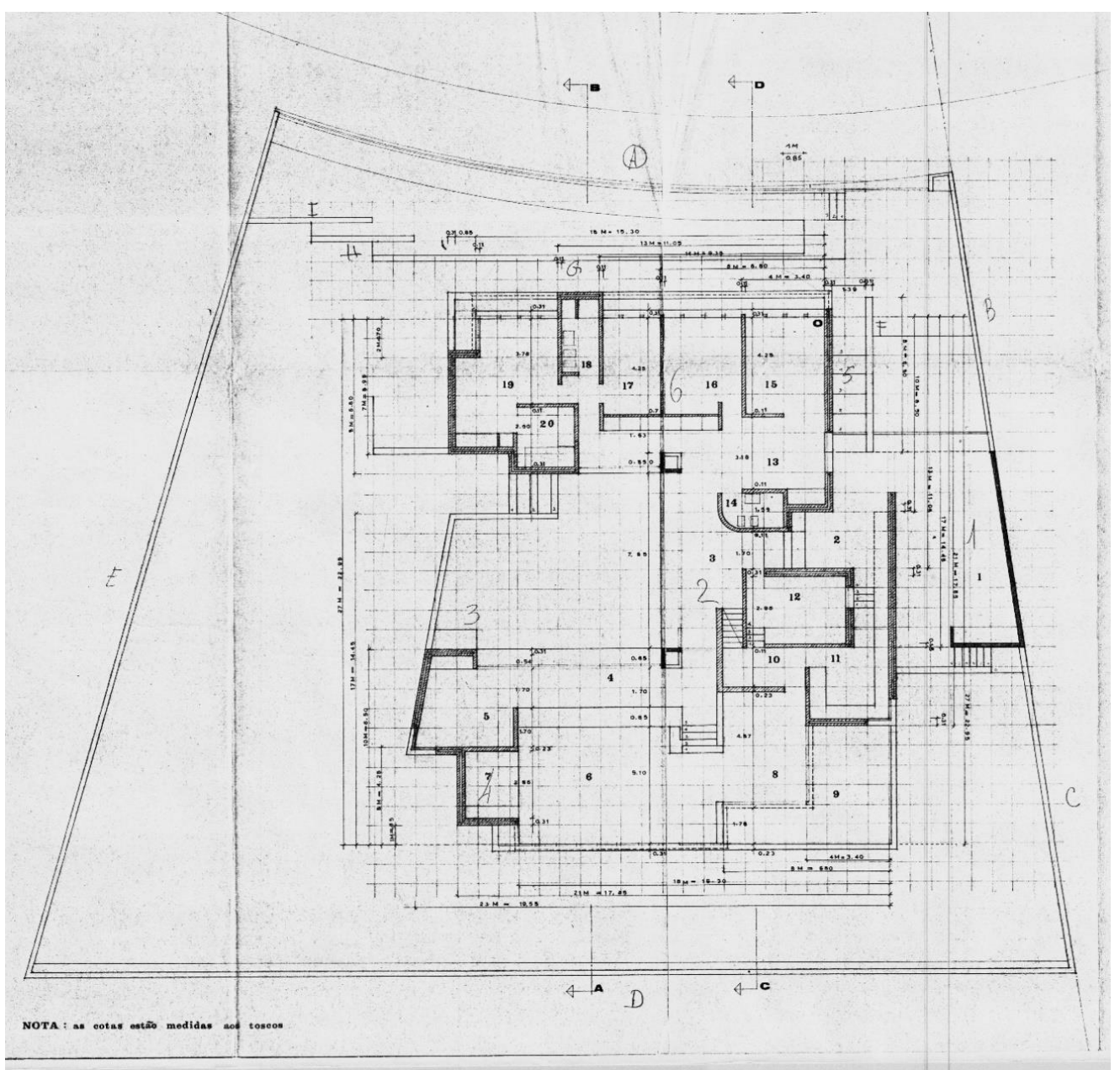

Figure 8. Gallo House Architectural Drawing

Source: Câmara Municipal da Marinha Grande, Processo Camarário nº 1299/1969 [Marinha Grande Town Council, Process No. 1299/1969].

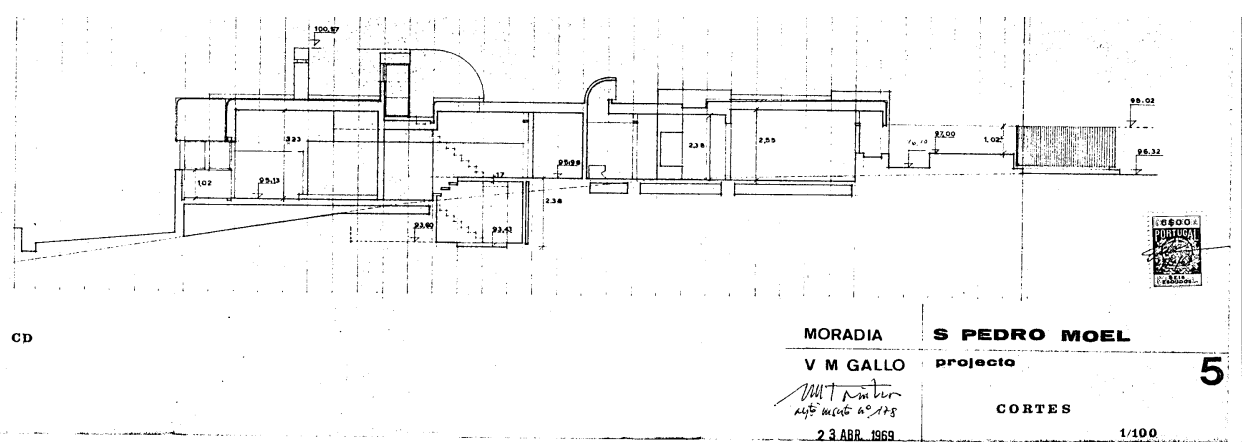

\section{Figure 9. Gallo House Architectural Drawing}

Source: Câmara Municipal da Marinha Grande, Processo Camarário nº 1299/1969 [Marinha Grande Town Council, Process No.1299/1969].

Despite this formal simplification, the composition remains complex and intricate, as is patent, for example, in the integration of the bathrooms as singular elements or in the spatial diversity of the living spaces. 
Likewise, whilst in an initial phase the possibility of different levels for the roof was raised, with the levels accompanying the slope of the land, the section drawing in Figure 4 advances the possibility of a single roof, slanting roof plane that accompanies the differences in level. That solution is transposed to the final version (Figure 9) but maintains the roof plane on one single level so as to gain ceiling height in the living spaces. At the same time, this solution unifies the interior spatiality, a principle learnt from the Maison Carré, as mentioned above. With the same aim of unifying the internal space, the reduction in the number of interior levels to one single split level space in the living area also allowed for a more direct relationship between the various functional areas and the patio, as everything is on one and the same level.

The complex and organic geometry of the design is disciplined by the application of a rigid metric, a regulating module that serves to define, using multiples and sub-multiples of $0.85 \mathrm{~m}$, the exact placement of the various construction elements - the height of steps, ceilings and lowered ceilings, skirting boards, low stone walls and door and window spans. Indeed, the plan (in Figure 8) is based on a square module, whereby, in addition to the conventional elevation levels, the number of multiples in each dimension is identified. Curiously enough, the same module is also applied to the rough elements, with the coverings subsequently being applied in specific thicknesses, which reveals concern with rigour in the initial phase of the construction process.

All throughout this process, and despite the testing of multiple possibilities, one can verify that a group of design principles remains a constant. Manuel Tainha called these "formation principles"; they are:

1. Concentration of the built structure in the west of the plot, thus freeing up the remaining area for an outdoor space/garden

2. Adaptation of the house to the topography

3. Clear separation between private spaces, reception/living spaces and kitchen areas, taking their distinct purposes into account

4. A surprise effect in accessing the house: the inside of the house must not be seen from the plot entrance, with only the final inflection in the path to the house making this possible

5. Location of the living spaces facing the landscape, in an attempt to manage the contradiction between exposure to the direction the house most requires protection from and is most advantageous for the house - the house is born out of the struggle against the place

6. The patio as a central, exterior structuring space that determines the organisation of the interior spaces that communicate with it and establish relationships with each other through it

7. Desire for great variety in interior spatial ambiences, making the most out of the different light sources, view lines, changes in height and elevation, etc.

These "formation principles" are a set of rules defined by Tainha that depend on place, programme, culture, taste, emotions, experience; they serve to help 
formulate a response to a certain problem that is to be resolved. These rules become relational logics, the founding logics of the design project, whose malleability - which results from their level of abstraction - makes it possible to adopt a number of alternative for one and the same situation, whilst at the same time allowing for work in the design process with a certain degree of security, linking what has already been done to that which can still be done in the future.

It was established over the course of this investigation project that the design process does not follow a linear course; it does not strictly adhere to principles of cause and effect or deductive logic. It is a bumpy path, one that involves a complex web of questions, variable in configuration, the response to which is achieved through successive approach attempts. As this course is sustained, in most cases, by an intuitive procedure - "intuitive logic" - the guarantor of coherence of the architectural solution results from the "formation principles" that guide the production of the proposal. They guide it. But, not as a prior and autonomous iteration of the representation, but rather engendered by the representation itself. Thus, the variable configuration of this web of questions; thus, the malleability of the process; and thus, its unpredictability.

\section{Conclusions}

However, one should point out, also by way of a summary, that the reconstruction of the drawing web, which in end effect is the thought process web, revealed a design process that is non-linear - at times erratic, full of advances and retreats, contradictions, chance situations, hesitations and discontinuities. This picture is, of course, more evident in the early design phases, but it is also recognisable in the more advanced phases, even when everything seemed to have its definitive configuration. As was typical for him, Tainha extended the definition process for the Gallo House even into the construction phase. The only thing that seemed to guarantee order in the process from the outset was a certain number of design principles, deemed by Tainha as "formation principles". But those principles are also generated in the drawings. The thought seeks in the drawing both a possibility of order and, simultaneously, a process of constant questioning. And that process continues on until the design task is considered to be effectively completed. One must, however, state that that particular relationship with the design would seem to be consciously convoked.

So it is this two-fold possibility - of order and constant questioning, at the same time - that Tainha recognises, simultaneously acknowledging the connection between drawing and thought.

To cite Tainha: "[it is] in the act of representation that ideas become clearer... or are lost, considering that representing what one thinks and thinking what one represents are, when they occur, one and the same thing" 27.

27. Author's own translation. Original text: “É no acto de representação que a deia se clarifica... ou se perde, posto que representar o que se pensa e pensar o que se representa, são na ocorrência, uma e a mesma coisa". Tainha, Manuel Tainha, Textos de Arquitectura (Casal de Cambra: Caleidoscópio, 2006), 122. 
I return to the questions that served as the basis for this project - the value of the drawing in the ultimate definition of the Gallo House. By choosing it as his support, the drawing enabled Tainha to confront the lack of definition in his thoughts, and incorporate the unpredictability that marks its evolution; in other words, to work with its ambiguity.

In the drawing Tainha sought to establish an order for the definition of this work; but it was also through the drawing that he challenged said definition with its own feasibility. It is therein that one should understand the value of the drawing in the Gallo House design project.

I will conclude by returning to the title of this paper: 'Thinking as drawingreflections on a drawing that no longer exists'. I believe that Tainha's approach to the drawing is perhaps less predominant in today's world, even if it continues to be used in practice by referential contemporary architects. But I do not believe that that type of drawing, which no longer exists, should be the object of mere nostalgia. The value of the drawing in the design thought process, which coincides with the value that the representation of architecture should have, should be identified not in the virtuosity with which it approximates the represented object, but in its capacity for enabling the creator to work with the lack of definition that said object will have throughout the design process. A representation that corresponds precisely to its own object is of no use in the architect's design thought process.

The representation leads to the thought; it is the latter's beginning. However, the design thought process does not end in the representation.

\section{Acknowledgments}

This work is financed by national funds by FCT - Foundation for Science and Technology under the Project UID/AUR/04026/2013.

\section{Bibliography}

Aalto, A. "Architettura e Arte Concreta." [Architecture and Concret Art.] Domus 2235(Dec) (1947): 103-115.

Aalto, A. 'L'Oeuf du Poisson et le Saumon." [The Fish Egg and the Salmon.] Das Werk: Architektur und Kunst 36(2) (1949): 43-44.

Aalto, A. "O Ovo de Peixe e o Salmão." [The Fish Egg and the Salmon.] Arquitectura 46 (Feb) (1953): 15-16.

Evans, R. Translations from Drawings to Building and Other Essays. London: Architectural Association, 1997.

Forty, A. Words and Buildings: A Vocabulary of Modern Architecture. London: Thames and Hudson, 2001.

Herbert, D. Architectural Study Drawings. New York: Van Nostrand Reinhold, 1993.

Quinta, E. S. Pedro de Moel: Um Refúgio Moderno. [S. Pedro de Moel: A Modern Refuge.] Master Dissertation. Faculdade de Ciências e Tecnologia da Universidade de Coimbra, 2010. Available at: https://core.ac.uk/download/pdf/19130132.pdf.

Robbins, E. Why Architects Draw. Cambridge and London: MIT Press, 1994. 
Rodeia, J. B. “A House on the Beach - With regard to Manuel Tainha's Architecture." In Manuel Tainha: Projectos 1954-2002. Edited by J. Neves. Porto: Edições Asa: 2002, 27-35.

Tainha, M. Memória Descritiva. [Project Description.] Marinha Grande: Câmara Municipal da Marinha Grande, Processo camarário no 1299/1969, 1969.

Tainha, M. "Interview with João Belo Rodeia for Jornal Arquitectos." Architects Journal 152 (1995): 24-32.

Tainha, M. Manuel Tainha, Textos de Arquitectura. [Manuel Tainha, Texts on Architecture.] Casal de Cambra: Caleidoscópio, 2006. 